\title{
PROFICIENCY OF BIPLOT METHODS (AMMI AND GGE) IN THE APPRAISAL OF TRITICALE GENOTYPES IN MULTIPLE ENVIRONMENTS
}

\author{
KENDAL, E. $.^{*}-$ TEKDAL, S. $^{2}-$ KARAMAN, M. $^{3}$ \\ ${ }^{I}$ Mardin Artuklu University, Department of Plant and Animal Production, Kiziltepe Vocational \\ and Training High School, Mardin, Turkey \\ ${ }^{2}$ GAP International Agricultural Research and Training Center, 21100 Diyarbakir, Turkey \\ ${ }^{3}$ Muş Alparslan University, Faculty of Applied Sciences, Department of Plant and Production \\ Technologies, Mus, Turkey \\ *Corresponding author \\ e-mail: enver21_1@hotmail.com \\ (Received $8^{\text {th }}$ Feb 2019; accepted $21^{\text {st }}$ Mar 2019)
}

\begin{abstract}
The AMMI (additive main effect and multiplicative interaction) and GGE (genotype, genotype $\mathrm{x}$ environment) biplot analyses were used to evaluate and identify stability and yield of Triticale genotypes at three different locations throughout two years (2014-15-2015-16). The AMMI analysis of variance showed significant genotype, environment and GE interaction and indicated 1.31, 98.40 and $0.28 \%$ of total variation, respectively. The GGE bi-plot analysis indicated $78.19 \%$ of the total variation (PC1 (priciple component) 50.01\%, and PC2 26.08\%). This study has been useful to discriminate genotypes with superior and stable yield evaluated by the AMMI analysis and yield stability index incorporating the AMMI stability value and yield capacity in a single non-parametric index. The AMMI analysis indicated that G4, G8 (candidate) and G6 were found to be quite promising genotypes. In the GGE biplot analysis genotypes were investigated in two mega-environments, and the first megaenvironment covered E3, E5 and E6, and the second mega-environment covered E1, E2 and E4. The genotypes G6, G8, G9 and G11 were the wining genotypes in ME (mega-environment) I, G3, G4 and G12 and in ME II. The GGE and AMMI biplot approaches let us to describe the best genotypes, and G8 to be stable and high yielding for both ME, G6 only for ME I, G4 only for ME II and can be recommended to release as a cultivar.
\end{abstract}

Keywords: stability, interaction, yield, multi, approach

\section{Introduction}

In order to ensure an adequate and balanced diet of the growing world population, food production should be increased in parallel. This is possible through the development and application of new cultivation techniques and also by the development of more efficient and high quality plant species. For this purpose, Triticale ( $\mathrm{x}$ Triticosecale Wittmack), was developed as a new species, a hybrid of wheat and rye, used as an alternative cereal crop for growing in marginal areas (Kendal and Sayar, 2016). This new species is known that it is tolerant to diseases, pests, dry conditions, acid and problematic soils and it was determined that it could replace cereal forage crops. Triticale is mostly used in animal feeding and it is also evaluated as grain, roughage, silage and straw. The feed value of triticale is equivalent to corn, wheat, barley, rye and sorghum or better than them, while in feed rations, it can be preferred instead of corn, wheat, barley, rye and oats. Triticale is used primarily as animal feed, 
and in recent years it has also been used in human food and ethanol production (Oral, 2018).

Triticale cultivation in the world has shown an increase of over $40 \%$ in the last a decade years. The area of cultivation of triticale is 3.8 million ha, and the production is around 14.7 million tons in the world, and this rate is increasing day by day (Anonymus 2; Ayalew et al., 2018). In Turkey, statistical data related to triticale production have started to be given after 2004, and in 2016, about 38.000 ha area was planted and about 125.000 tons of product was obtained from this area. However, in our country, Triticale is the highest yield in cereals and grain yields approximately $3360 \mathrm{~kg}$ per hectare (Anonymous 1; Kizilgeci, 2019). Therefore, triticale is gaining more and more attention both in the world and in our country.

The exploiting of heredity instability is one of the very significant issues in terms of breeding strategies and this situation can only be explained by phenotypically phrase (Rad et al., 2013). In order to explain the phenotypic variations, it is highly dependent on the effect of the environments. Explaining this diversity is upwards sophisticated by the fact that all genotypes don't react in the same way as change in circles and the two environments do not have exactly the same conditions (Neisse et al., 2018). If the performance of genotypes changes in different location, then the interaction of the genotype location is an important factor in plant breeding strategies. Therefore, analysis of any variance combined can measure GEI and identify main effectiveness, however it is not enough to declare the GEI effectiveness. A convenient analytic pattern like the additive main effects and multiplicative interaction (AMMI) can cure both the additive main effect and multiplicative interaction constituent utilize the ANOVA (analysis of variance) and IPCA (Interaction Principal Components), respectively (Kilic, 2014; Mohammadi et al., 2018). The GGE biplot exploits the PCA approach to investigate the multi environment data and allow the visual presentation of the relationship among genotypes, environments and interaction as well as.

The aim of this study were to (i) analyses the effect of GEI on grain yield of 12 triticale genotypes by two new biplot models (AMMI and GGE) (ii) identifying high yielding and stable triticale genotype(s) across locations and (iii) to detect appropriate genotype(s) for every location or environment.

\section{Material and Methods}

The ten spring triticale advanced lines and two local check were evaluated in three locations across two years (2014-2015 and 2015-2016 growing seasons). The information of genotypes showed in Table 1. The trials were planted following a randomized complete block design with four replications at each location. The information about test location is given in Table 2. Each parcel was set in a six row plot of 6 meter length and $1.2 \mathrm{~m}$ diameter with plant spacing of $20 \mathrm{~cm}$. Sowing of trials were done in autumn and sowing density was used 500 seeds in per $\mathrm{m}^{-2}$. The fertilization of

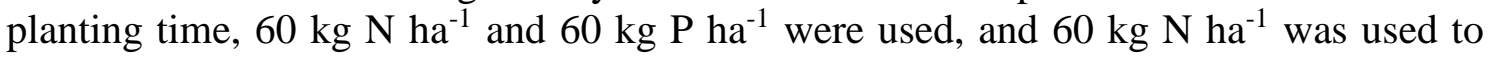
each plots at tillering time for all plots. The grain yield was recorded from each plot after harvesting of the materials and measured extrapolated to ton/ha.

\section{The described growing seasons 2014-2015}

The rainfall was the same with long term in all location and it was enough for germination of plant after sowing time in October, the triticale had good weather in 
winter days. Seasonal conditions were favorable for triticale cultivation in the development period in March and April in all location. Therefore, the expected high yield was obtained in all location of 2014-15 growing season. All location had good growing season, but in Ceylanpınar location the rainfall is very low than other location and it was partially heat stress during after heading time, in Adiyaman location during the spring period there was partially heat stress, In Diyarbakir location, conditions were more favorable than other locations.

Table 1. The code, name/pedigree of triticale genotypes

\begin{tabular}{|c|c|c|}
\hline Code & Name of cultivar and pedigree of lines & Orijin \\
\hline G1 & $\begin{array}{c}\text { LIRON_2/5/DIS B5/3/SPHD/PVN/YOGUI_6/4/ } \\
\text { CTSS04Y00163S-102Y-06M-06Y-2M-3Y-0M-0SD-0SD-0SD }\end{array}$ & CIMMYT \\
\hline G2 & $\begin{array}{c}\text { PRESTO//2*TESMO_1/MUSX 603/4/ARDI_1/... } \\
\text { CTSS03Y00091T-050TOPY-5M-2Y-06Y-5M-1Y-0M-0SD-0SD-0SD }\end{array}$ & CIMMYT \\
\hline G3 & $\begin{array}{c}\text { LIRON_2/5/DIS B5/3/SPHD/PVN/YOGUI_6/4/ } \\
\text { CTSS03Y00033T-A-62M-1Y-06Y-2M-4Y-0M-0SD-0SD-0SD }\end{array}$ & CIMMYT \\
\hline G4 & $\begin{array}{c}\text { TURACO/CENT.SARDEV/7/LIRON_2/5/DIS B5/3/... } \\
\text { CTSS02B00186T-8Y-3M-3Y-4M-1Y-0M-0SD-0SD-0SD }\end{array}$ & CIMMYT \\
\hline G5 & Tacettinbey(check) ----------Cukurova University & TURKEY \\
\hline G6 & 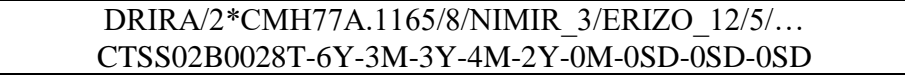 & CIMMYT \\
\hline G7 & $\begin{array}{c}\text { LIRON_2/5/DIS B5/3/SPHD/PVN/YOGUI_6/4/ } \\
\text { CTSS02B00413S-22Y-2M-3Y-1M-2Y-0M-0SD-0SD-0SD }\end{array}$ & CIMMYT \\
\hline G8 & $\begin{array}{c}\text { HX87-244/HX87-255/5/PRESTO//2*TESMO_1/... } \\
\text { CTSS03SH00028S-25Y-2M-4Y-3M-1Y-0M-0SD-0SD-0SD }\end{array}$ & CIMMYT \\
\hline G9 & $\begin{array}{c}\text { HX87-244/HX87-255/7/LIRON_2/5/DIS B5/3/SPHD/... } \\
\text { CTSS03SH00030S-17Y-3M-4Y-3M-1Y-0M-0SD-0SD-SD }\end{array}$ & CIMMYT \\
\hline G10 & Presto(check) Transitional Zone Agricultural Research Institute & TURKEY \\
\hline G11 & $\begin{array}{c}\text { LIRON_2/5/DIS B5/3/SPHD/PVN/YOGUI_6/4/... } \\
\text { CTSS03Y00036T-A-1M-2Y-06Y-2M-4Y-0M-0SD-0SD-0SD }\end{array}$ & CIMMYT \\
\hline G12 & $\begin{array}{c}\text { LIRON_2/5/DIS B5/3/SPHD/PVN/YOGUI_6/4/... } \\
\text { CTSS03Y00036T-A-1M-4Y-06Y-4M-1Y-0M-0SD-0SD-0SD }\end{array}$ & CIMMYT \\
\hline
\end{tabular}

Table 2. Years, sites, codes and coordinate status of environments

\begin{tabular}{c|c|c|c|c|c|c}
\hline Years & $\begin{array}{c}\text { Code of } \\
\text { Sites }\end{array}$ & Sites & $\begin{array}{c}\text { Altitude } \\
(\mathbf{m})\end{array}$ & Latitude & Longitude & $\begin{array}{c}\text { Averag. of pers. } \\
(\mathbf{m m})\end{array}$ \\
\hline \multirow{2}{*}{$2014-$} & E1 & Diyarbakır & 612 & $37^{\circ} 55^{\prime} \mathrm{N}$ & $40^{\circ} 14^{\prime} \mathrm{E}$ & 584.2 \\
2015 & E2 & Adiyaman & 669 & $37^{\circ} 76^{\prime} \mathrm{N}$ & $38^{\circ} 27^{\prime} \mathrm{E}$ & 540.3 \\
& E3 & Ceylanpınar & 366 & $36^{\circ} 84^{\prime} \mathrm{N}$ & $40^{\circ} 05^{\prime} \mathrm{E}$ & 306.0 \\
\hline \multirow{2}{*}{$2015-$} & E4 & Diyarbakir & 612 & $37^{\circ} 55^{\prime} \mathrm{N}$ & $40^{\circ} 14^{\prime} \mathrm{E}$ & 417.2 \\
2016 & E5 & Adiyaman & 669 & $37^{\circ} 76^{\prime} \mathrm{N}$ & $38^{\circ} 27^{\prime} \mathrm{E}$ & 402.4 \\
& E6 & Ceylanpınar & 366 & $36^{\circ} 84^{\prime} \mathrm{N}$ & $40^{\circ} 05^{\prime} \mathrm{E}$ & 217.0 \\
\hline
\end{tabular}

\section{The described growing seasons 2015-2016}

The rainfall of second season was late in planting time and it was low, in development of plant time, when we compare it with long term rainfall of locations. On the other hand; the temperature was high. Genotypes were exposed to drought in Ceylanpinar location. In the Adiyaman location, it was partially exposed to temperature stress. In Diyarbakır, heat stress was effective after heading period in April. Therefore, the grain yield of 2014-2015 season was suitable than 2015-16 growing season in all locations. The conditions of Ceylanpinar location is usually hard than other location, because the total of rainfall of seasons usually is low (Table 2). 


\section{Statistical analysis (AMMI and GGE)}

The AMMI analysis was carried out using the adjusted mean values of grain yield to detect the relation among genotypes, locations and GEI over model designated by Zobel et al. (1988). The adopted method uses PCA to decompose the multiplicative effects of GEI into a number of IPCA. The two models (AMMI and GGE) analysis were carried out by Genstat software (version 12). The Additive mean effect and multiplicative interaction model analysis is based on the following formula; $\mathbf{Y}_{\text {ger }}$ $=\mu+\alpha \mathrm{g}+\boldsymbol{\beta}_{\mathrm{e}}+\boldsymbol{\Sigma}_{\mathrm{n}} \boldsymbol{\lambda}_{\mathrm{n}} \boldsymbol{\gamma}_{\mathrm{gn}} \boldsymbol{\delta}_{\mathrm{en}}+\boldsymbol{\varepsilon}_{\mathrm{ger}}+\boldsymbol{\rho}_{\mathrm{ge}}$; where, Yger is the monitored grain yield of genotype (g) in environment (e) for replication (r); Additive parameters: $\mu$ is the grand mean; $\alpha \mathrm{g}$ is the deviation of genotype $\mathrm{g}$ from the grand mean, $\beta \mathrm{e}$ is the deviation of the environment e; Multiplicative parameters: $\lambda \mathrm{n}$ is the singular value for IPCA, $\gamma g n$ is the genotype eigenvectorfor axis $\mathrm{n}$, and $\delta \mathrm{en}$ is the environment eigenvector; $\varepsilon_{\text {ger }}$ is error term and $\rho_{\text {ge }}$ is PCA residual.

AMMI Stability Value (ASV) is the space from the origin to the coordinate point in a two dimensional plot of to IPCA scores (Purchase, 1997). Because the IPCA1 score contributes to the sum of squares of GEI, a weighted value is needed. This weighted value was calculated for each genotype and each environment according to the relative contribution of IPCA1 to IPCA2 to the interaction sum of squares as follows:

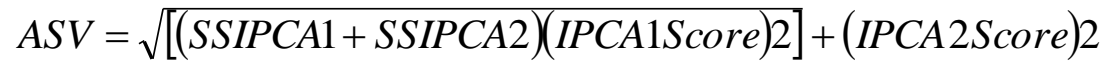

Where, / $\mathrm{SS}_{\text {IPCA1 }} / \mathrm{SS}_{\mathrm{IPCA} 2}$ is the weight given to the IPCA1-value by dividing the IPCA1 sum of squares by the IPCA2 sum of squares (Purchase, 1997).

Genotypic stability index (GSI) incorporate mean and stability index in a single criteria and calculated as: GSI $=$ RASV + RY where, RASV is the rank of ASV and RY is the rank of mean yield of genotypes across environments. This index considered the rank of AMMI stability value to rank genotypes based on grain yield across environments.

On the other hand; data were graphically analyzed to interpret GEI to identify stable and adaptive genotypes using the GGE biplot described by Yan and Tinker (2006). The GGE biplot methodology (Yan et al., 2000) was applied for analysis of GE interaction of grain yield. The GGE biplot model is based on the following formula:

$$
K(Y i j)=\mu+\beta j+K \sum \delta k \gamma i k \eta j \mathrm{k} \mathrm{k}+1
$$

where $E(Y i j)$ is the expectation value of genotype $i$ in environment $j ; \mu$ is the grand mean; $\beta j$ is the environment effect; $\mathrm{K}$ stand for the number of principal the environment effect; $K$ stand for the number of principal components (PC) needed to provide an adequate explanation of $\mathrm{G}+\mathrm{GE}$; is singular value for the kth PC; and stands for the $\delta k$ $\gamma \mathrm{jk}$ ith genotype score and stands for the jth environmental score for the kth PC. Singular value $\eta j \mathrm{k}$ partitioning is achieved by providing a scaling factor $f$ to obtain alternative genotype $\left(\mathrm{c}_{\mathrm{ik}}=\delta_{\mathrm{k}}^{\mathrm{f}}\right.$ and environment scores. The symmetric scaling $(\mathrm{f}=0.5)$ was used in $\gamma i k)\left(\mathrm{d}_{\mathrm{j} k}=\delta^{1} \mathrm{k}^{-\mathrm{f}} \eta j k\right)$ visualizing which-wins-where pattern of MET data, due to its compliance with most of the features related to other benchmarking methods (Yan, 2002). 


\section{Result}

\section{The AMMI analysis}

The variance of AMMI analysis showed that genotype, environment, GEI and IPCA (Interaction principle component analysis) had significant $(\mathrm{p}<0.01)$ effect on triticale grain yield of 12 genotypes tested in six environments (Table 3). The environment main effect accounted for $98.40 \%$ of total variation, compared with $1.31 \%$ for genotype and $0.28 \%$ for GE interaction effects in the analysis of combined variance (Table 3). The quantity of genotypic effect was about two times greater than the GEI effect, which indicates different possible presence of MEs in the METs data. The major differences between the circles influenced the average of squares and caused the grain yield of each environment to change. The multiplicative variance of the treatment sum of squares due to interaction was partitioned into the fourth interaction principal components and the only one of them significant effect. The first PCs accounted for $56.75 \%$, the second for $17.56 \%$, the third for $17.11 \%$, and the fourth only $8.55 \%$ of G+GE total variation for triticale data. Except the first IPCA-I, the remaining three IPC axes were non-significant and contributed $43.22 \%$ of the GEI (Table 3 ).

Table 3. The analysis of variance for grain yield using AMMI model

\begin{tabular}{c|c|c|c|c|c}
\hline Source & df & SS & MS & F & G+E+GE SS explained (\%) \\
\hline Total & 287.00 & 1091.60 & 3.80 & - & - \\
Treatments & 71.00 & 1024.40 & 14.43 & 55.80 & - \\
\hline Genotypes & 11.00 & 28.40 & 2.58 & $9.98^{* *}$ & 1.31 \\
Environments & 5.00 & 965.60 & 193.11 & $216.61 * *$ & 98.40 \\
Block & 18.00 & 16.00 & 0.89 & 3.45 & - \\
Interactions & 55.00 & 30.40 & 0.55 & $2.14 * *$ & 0.28 \\
IPCA 1 & 15.00 & 19.00 & 1.26 & $4.89 * *$ & 56.75 \\
IPCA 2 & 13.00 & 5.00 & 0.39 & $1.50 \mathrm{~ns}$ & 17.56 \\
IPCA 3 & 11.00 & 4.20 & 0.38 & $1.46 \mathrm{~ns}$ & 8.11 \\
IPCA 4 & 9.00 & 1.80 & 0.19 & $0.75 \mathrm{~ns}$ & - \\
Residuals & 7.00 & 0.50 & 0.07 & 0.27 & - \\
Error & 198.00 & 51.20 & 0.26 & - & -
\end{tabular}

df - degrees of freedom; SS - sum of squares; MS - mean square. **, p<0.01; G - genotypes; E environments

In the AMMI model, the figure interpret by two direction and $\mathrm{x}$-axis represents the genotypes and environment main effect and y-axis represents the effects of interaction (Fig. 1). The genotypes and environment indicated much more variability in both main effect and interaction. The environment located above the $y$-axis mean that they are desirable and high-efficient, whereas the environments, which are located under of $y$-axis mean that they are unffavorable and low-yielding (Kendal and Tekdal, 2016). According to these definitions, in the AMMI (Fig. 1) indicated that grain yield of the first year (7.244 t/ha) is higher than in the second year $(3.979 \mathrm{t} / \mathrm{ha})$ in all locations (Fig. 1 and Table 4). When we evaluate the locations based on grain yield average, all locations were located above average (y axis) in the first crop season (2014-15), while all location were located under average (y axis) in the second crop season (2015-16). This implies that grain yield of first year in all locations were higher than the second year. On the other hand, when we evaluate the environments independently, the highest yield average is obtained from E1 and the lowest yield average is obtained from E6. 
According to the location averages, Diyarbakir location $(6.529 \mathrm{t} / \mathrm{ha})$ is found to be more efficient than the other two locations in both years (Fig. 1 and Table 5). The AMMI (Fig. 1) also shows the stability of genotype based on mean grain yield of multiple environments. The genotypes located near the $x$-axis and on the right of the $y$-axis mean that they are stable and high-efficient, whereas the genotypes, which are located far from $x$-axis and left side of $y$-axis mean that they are unstable and low-yielding (Crossa et al., 1990). Accordingly, G7, G4 and G8 placement of near $x$ axis and on the right of the $y$-axis, therefore it mean that these genotypes are quite stable and yielding. Moreover; G1, G3, G10 (check) and placement of far from x axis, so these genotypes are unstable across environments. The AMMI (Fig. 1) biplot showed that G4, G6 and G8 are quite yielding, while both of check used in the study (G5 and G10) are poorest genotypes across test environments (Table 4).

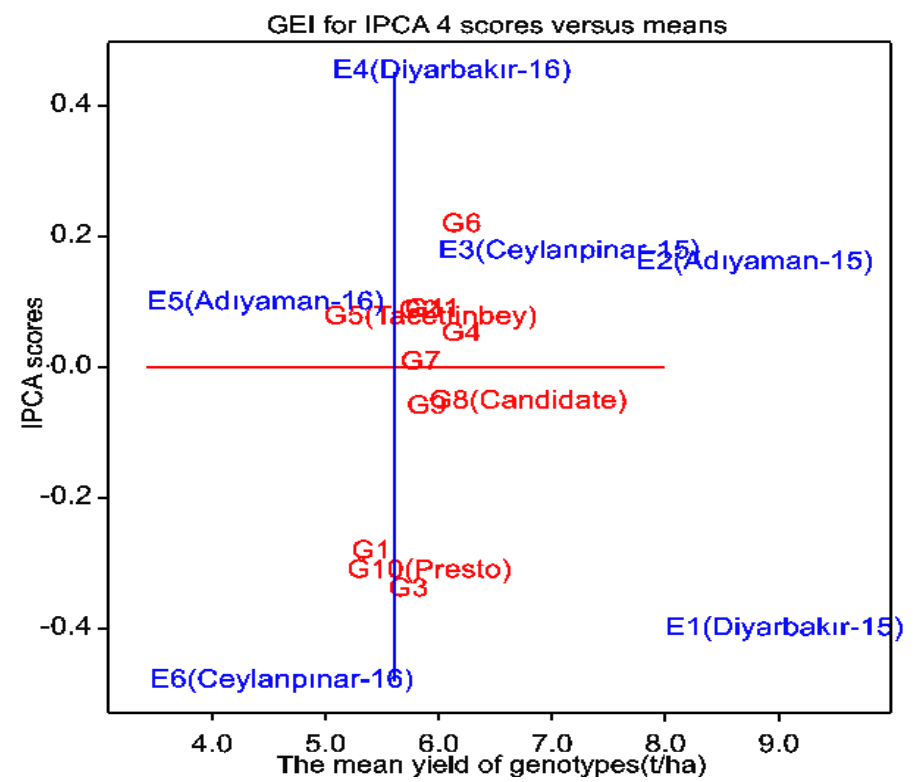

Figure1. The AMMI shows the stability of genotype based on mean grain yield of multiple environments. The genotypes located near the $x$-axis and on the right of the $y$-axis mean that they are stable and high-efficient, whereas the genotypes, which are located far from $x$-axis and left side of y-axis mean that they are unstable and low-yielding. G1-G12 is the codes for the triticale disomic addition lines and G5 and G10 used as the control, respectively. E1-E3 are environment codes for 2014-15, E4-E6 for 2015-16 growing season

Table 4. The genotype means and IPCA scores based on six environments

\begin{tabular}{c|c|c|c|c|c}
\hline Genotypes & Gen mean & IPCAg[1] & IPCAg[2] & IPCAg[3] & IPCAg[4] \\
\hline G1 & 5.228 & 0.31884 & 0.21680 & -0.37392 & -0.28371 \\
G2 & 5.644 & 0.35121 & -0.47205 & 0.00288 & 0.08386 \\
G3 & 5.553 & -0.62687 & -0.41001 & 0.10880 & -0.34148 \\
G4 & 6.022 & -1.08531 & 0.33717 & 0.08051 & 0.04918 \\
G5 & 4.984 & 0.34995 & 0.37082 & 0.64101 & 0.07483 \\
G6 & 6.022 & 0.29643 & 0.34783 & -0.12295 & 0.21614 \\
G7 & 5.660 & 0.16724 & -0.40324 & 0.39346 & 0.00543 \\
G8 & 5.911 & 0.05858 & -0.04726 & -0.23521 & -0.05409 \\
G9 & 5.714 & -0.03673 & 0.29583 & -0.09229 & -0.06228 \\
G10 & 5.188 & 0.32915 & 0.08225 & 0.11694 & -0.31300 \\
G11 & 5.699 & 0.04626 & -0.12553 & -0.44469 & 0.08626 \\
G12 & 5.713 & -0.16875 & -0.19261 & -0.07455 & 0.53887 \\
\hline
\end{tabular}


Table 5. AMMI-estimates per environment(yield(t/ha) across years and locations)

\begin{tabular}{|c|c|c|c|c|c|c|c|c|c|c|c|c|}
\hline \multirow{3}{*}{$\begin{array}{l}\text { Geno- } \\
\text { types }\end{array}$} & \multicolumn{4}{|c|}{ Diyarbakır } & \multicolumn{4}{|c|}{ Adiyaman } & \multicolumn{4}{|c|}{ Ceylanpınar } \\
\hline & \multicolumn{2}{|c|}{$\begin{array}{c}\text { (E1) } \\
2014-15\end{array}$} & \multicolumn{2}{|c|}{$\begin{array}{c}(\mathrm{E} 4) \\
2015-16\end{array}$} & \multicolumn{2}{|c|}{$\begin{array}{c}(\mathrm{E} 2) \\
2014-15\end{array}$} & \multicolumn{2}{|c|}{$\begin{array}{c}\text { (E5) } \\
2015-16\end{array}$} & \multicolumn{2}{|c|}{$\begin{array}{c}\text { E3) } \\
2014-15\end{array}$} & \multicolumn{2}{|c|}{$\begin{array}{c}\text { (E6) } \\
2015-16 \\
\end{array}$} \\
\hline & Yield & Rank & Yield & Rank & Yield & Rank & Yield & Rank & Yield & Rank & Yield & Rank \\
\hline G1 & 7.324 & G4 & 4.364 & G12 & 7.348 & G4 & 3.418 & G6 & 5.485 & G6 & 3.429 & G6 \\
\hline G2 & 7.927 & G3 & 5.337 & G4 & 7.196 & G6 & 3.797 & G8 & 6.044 & G7 & 3.563 & G8 \\
\hline G3 & 8.766 & G8 & 5.165 & G8 & 7.776 & G9 & 2.911 & G11 & 5.572 & G4 & 3.127 & G9 \\
\hline G4 & 9.105 & G7 & 5.471 & G2 & 9.178 & G8 & 2.978 & G2 & 6.127 & G8 & 3.272 & G2 \\
\hline G5 & 6.991 & G12 & 4.261 & G6 & 6.910 & G12 & 2.601 & G12 & 6.105 & G5 & 3.034 & G7 \\
\hline G6 & 7.914 & G9 & 5.333 & G7 & 8.246 & G11 & 4.072 & G9 & 6.581 & G9 & 3.986 & G11 \\
\hline G7 & 8.147 & G11 & 5.332 & G11 & 7.256 & G3 & 3.434 & G7 & 6.277 & G2 & 3.515 & G1 \\
\hline G8 & 8.258 & G2 & 5.339 & G3 & 8.033 & G1 & 3.910 & G1 & 6.122 & G12 & 3.806 & G10 \\
\hline G9 & 8.008 & G6 & 4.976 & G9 & 8.097 & G7 & 3.498 & G10 & 6.093 & G10 & 3.613 & G4 \\
\hline G10 & 7.419 & G10 & 4.414 & G10 & 7.041 & $\mathrm{G} 2$ & 3.117 & G4 & 5.762 & G11 & 3.376 & G12 \\
\hline G11 & 8.003 & G1 & 5.220 & G1 & 7.867 & G10 & 3.841 & G3 & 5.752 & G3 & 3.511 & G3 \\
\hline G12 & 8.089 & G5 & 5.529 & G5 & 7.945 & G5 & 3.543 & G5 & 6.007 & G1 & 3.165 & G5 \\
\hline Mean & 7.996 & & 5.062 & & 7.741 & & 3.427 & & 5.994 & & $\mathbf{3 . 4 5 0}$ & \\
\hline Mean & \multicolumn{4}{|c|}{6.529} & \multicolumn{4}{|c|}{5.584} & \multicolumn{4}{|c|}{4.722} \\
\hline Mean & \multicolumn{6}{|c|}{7.244} & \multicolumn{6}{|c|}{3.979} \\
\hline
\end{tabular}

\section{The GGE Biplot analysis}

The mean grain yield across two years (2014-15-2015-2016) in three location (Diyarbakır, Adıyaman, Ceylanpınar) of 12 triticale genotypes were showed in Table 5. These table data was used to generated a GGE biplot (Fig. 2-Fig. 6), although the genotype is compatible with biplot, it represents only $78.19 \%$ of the variation. In the present study, the first two IPCAS were used to portray genotype by environment interaction and placement on the (Fig. 2-Fig. 6). The GGE biplot provides good explanation of the pattern, regarding first two IPCs.

The relationships among and between genotypes and environments visualize in Fig. 2. A biplot such a graph to be interpreted bi-directionally has the following comments (Yan et al., 2000; Yan and Tinker, 2006). 1) The cosine of the angle between the vectors of the two environments approaches the Pearson correlation between them. Therefore, an angle of less than $90^{\circ}$ shows a positive correlation, an angle greater than $90^{\circ}$ shows a negative correlation and an angle of $90^{\circ}$ shows zero correlation. 2) If the vector of a environment is longer than other vectors, the variation of this environment on genotypes is higher than the other environments, if the vector length of any environment is very short than other traits vector then the variation of this environment is very low. 3) The angle between the vector of any genotype and any environment gives information about the state of the genotypes to environments.

If the angle is quite sharp and narrow indicates that the genotype is desirable for that environment if the angle is too large then the genotype is undesirable for that environment. 4) The length of the vector of a genotype indicates the strength or weakness of the genotype for all environments. According to these explanations there are high correlation among E3, E5, E6 and G6 is desirable for these environment, while there are high correlation E1, E2 and E4 and G6 is desirable genotype for these 
environments, and G8 (candidate) is desirable for all environments (Fig. 2 and Table 6). In Fig. 3, five sectors are created, with two sectors each of them consisting of three environments. These sectors stand for different MEs, because the winning genotypes for each sector are those positioned at the vertex we can say that G4 is wining genotype for sector II (E3, E5 and E6), G6 for sector I (E1, E2 and E4).

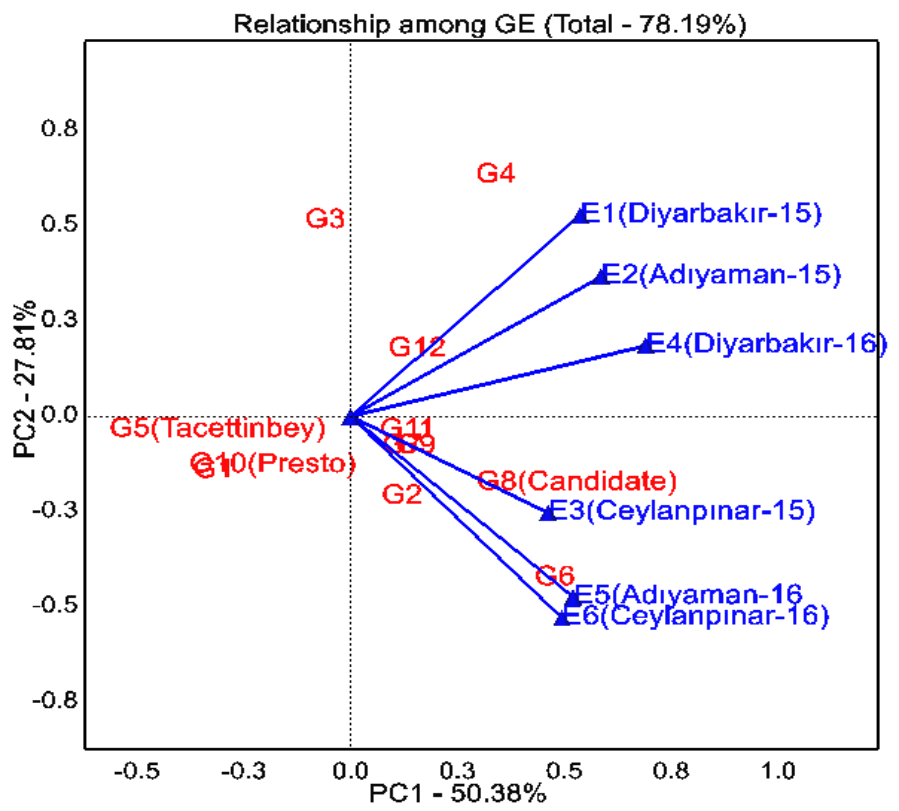

Figure 2. The GGE biplot which shows the relationships among test environments. The correlation coefficient between any two environments is approximated by the cosine of the angle between their vectors. Acute angles indicates a positive correlation, obtuse angles a negative correlation and right angles no correlation. G1-G12 is the codes for the triticale disomic addition lines and G5 and G10 used as the control, respectively. E1-E3 are environment codes for 2014-15, E4-E6 for 2015-16 growing season

Table 6. The first four AMMI selections for per environmts, variance and IPCA scors

\begin{tabular}{c|c|c|c|c|c|c|c|c|c|c|c}
\hline Env & Mean & Score & $\mathbf{1}$ & $\mathbf{2}$ & $\mathbf{3}$ & $\mathbf{4}$ & IPCAe[1] & IPCAe[2] & IPCAe[3] & IPCAe[4] & Variance \\
\hline E1 & 7.996 & -0.79 & $\boldsymbol{G 4}$ & $\boldsymbol{G 3}$ & $\boldsymbol{G 8}$ & $\boldsymbol{G 7}$ & -0.78881 & -0.44311 & 0.14583 & -0.40141 & 0.6423 \\
E2 & 7.741 & -0.75 & $\boldsymbol{G 4}$ & $\boldsymbol{G 6}$ & $\boldsymbol{G 9}$ & $\boldsymbol{G 8}$ & -0.74728 & 0.69354 & -0.32960 & 0.15858 & 0.5670 \\
E3 & 5.994 & 0.41 & $\boldsymbol{G 6}$ & $\boldsymbol{G 7}$ & $\boldsymbol{G 4}$ & $\boldsymbol{G 8}$ & 0.41209 & 0.30484 & 0.73113 & 0.17556 & 0.4741 \\
E4 & 5.062 & -0.14 & $\boldsymbol{G 1 2}$ & $\boldsymbol{G 4}$ & $\boldsymbol{G 8}$ & $\boldsymbol{G 2}$ & -0.14082 & -0.53822 & 0.06581 & 0.45130 & 0.4142 \\
E5 & 3.427 & 0.70 & $\boldsymbol{G 6}$ & $\boldsymbol{G 8}$ & $\boldsymbol{G 1 1}$ & $\boldsymbol{G 2}$ & 0.69460 & -0.18457 & -0.59209 & 0.09693 & 0.3242 \\
E6 & 3.450 & 0.57 & $\boldsymbol{G 6}$ & $\boldsymbol{G 8}$ & $\boldsymbol{G 9}$ & $\boldsymbol{G 2}$ & 0.57021 & 0.16753 & -0.02109 & -0.48096 & 0.2598 \\
\hline
\end{tabular}

Similar situation (two mega- environment) occured among environments presented in Fig. 4. The stability of genotypes also showed in Fig. 5, and generated by GGE biplot. The AEC is showing the stability genotypes based on across environment. The similar results indicated on Fig. 6, and G8 and G6 are favorable genotypes because they located near of center ideal center of biplot. The result showed that G8 (candidate) is quite stable and yielding, G6 and G4 are yielding as well as. The biplot showed that the selection of genotypes can be done both on specific and general goals. 


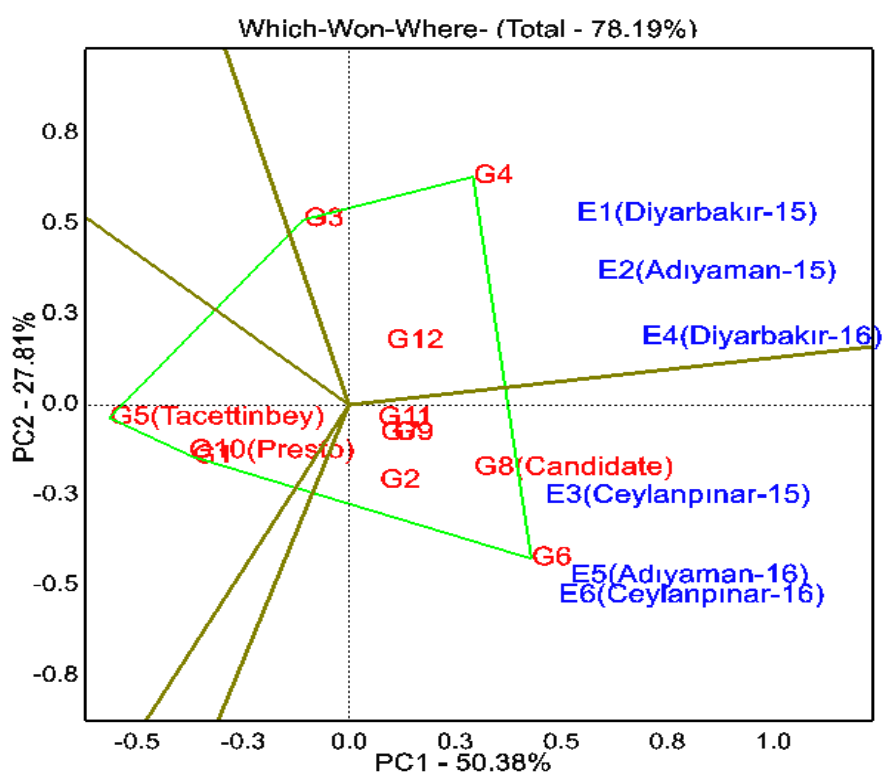

Figure 3. Which-won-where for genotypes and environments. The Polygon view of genotypeenvironment interaction for wheat-barley disomic addition lines over six test environments. The vertex genotype in each sector is the best genotype at environments whose markers fall into the respective sector. Environments within the same sector share the same winning genotype, and environments in different sectors have different winning genotypes. G1-G12 is the codes for the triticale disomic addition lines and G5 and G10 used as the control, respectively. E1- E3 are environment codes for 2014-15, E4-E6 for 2015-16 growing season

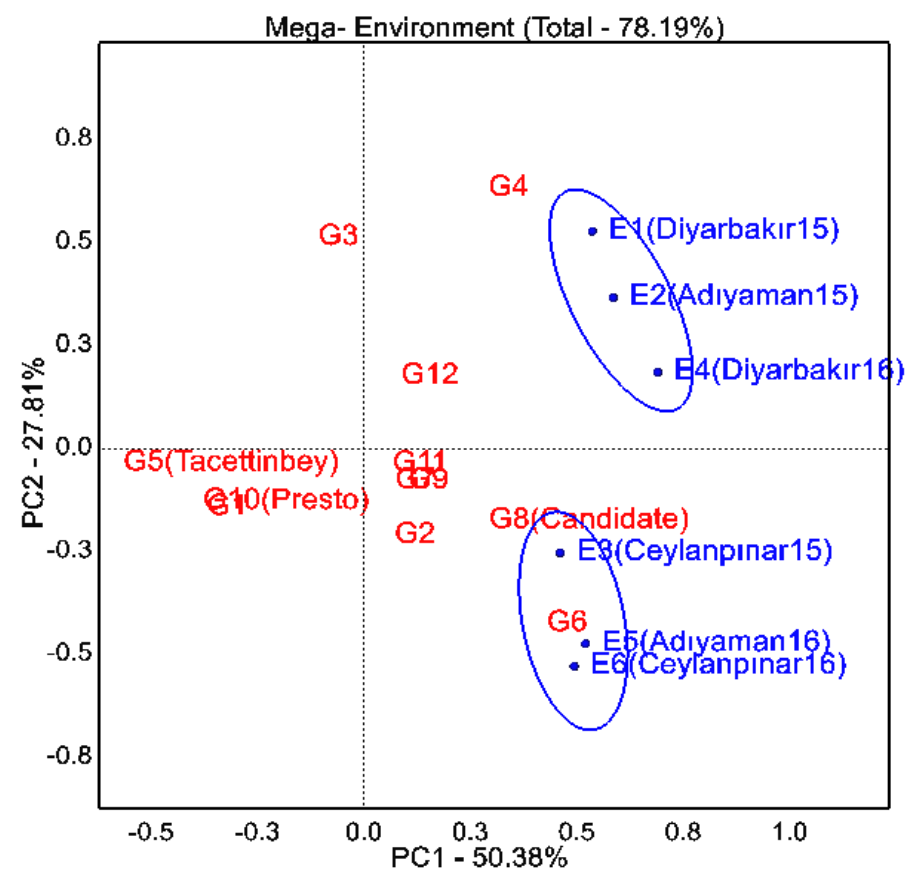

Figure 4. The potential mega-environments and ideal for mega environments. The environments which have same conditions located in the same mega-environment, and the genotypeswhich located in the center mega-center mean is desirable for this mega-environments. G1-G12 is the codes for the triticale disomic addition lines and G5 and G10 used as the control, respectively.

E1- E3 are environment codes for 2014-15, E4-E6 for 2015-16 growing season 


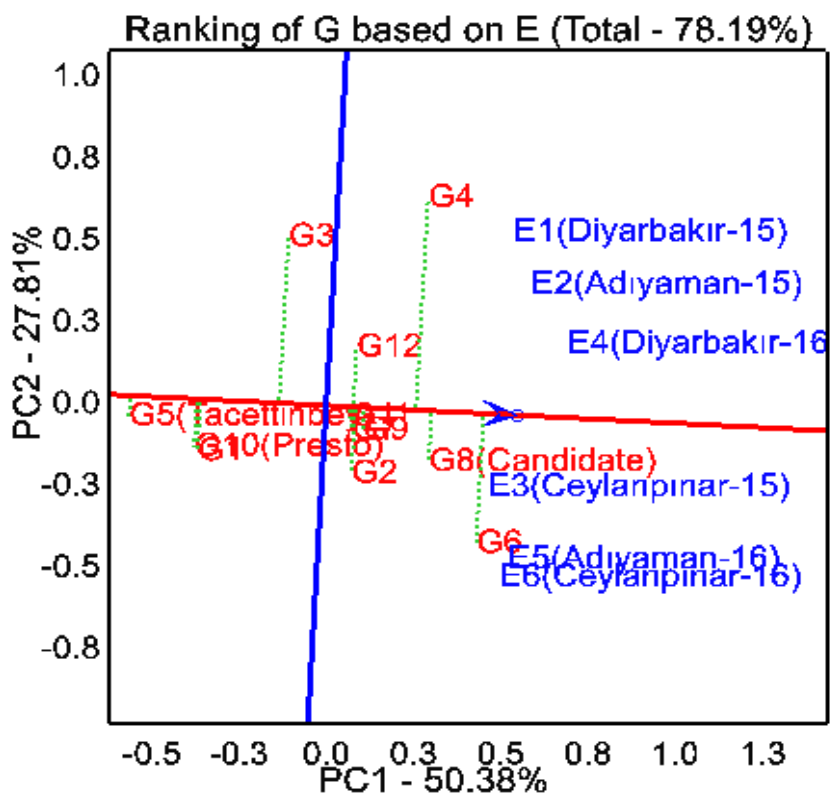

Figure 5. The GGE biplot showing the ranking of genotypes for both yield and stability performance over environments. The line passing through the biplot origin is called the average environment coordinate (AEC). More close to concentric circle indicates higher mean yield.

The line which passes through the origin and is perpendicular to the AEC with arrows represents the stability of genotypes. Either direction away from the biplot origin, on this axis, indicates greater GE interaction and reduced stability. G1-G12 is the codes for the triticale disomic addition lines and G5 and G10 used as the control, respectively. E1- E3 are environment codes for 2014-15, E4-E6 for 2015-16 growing season

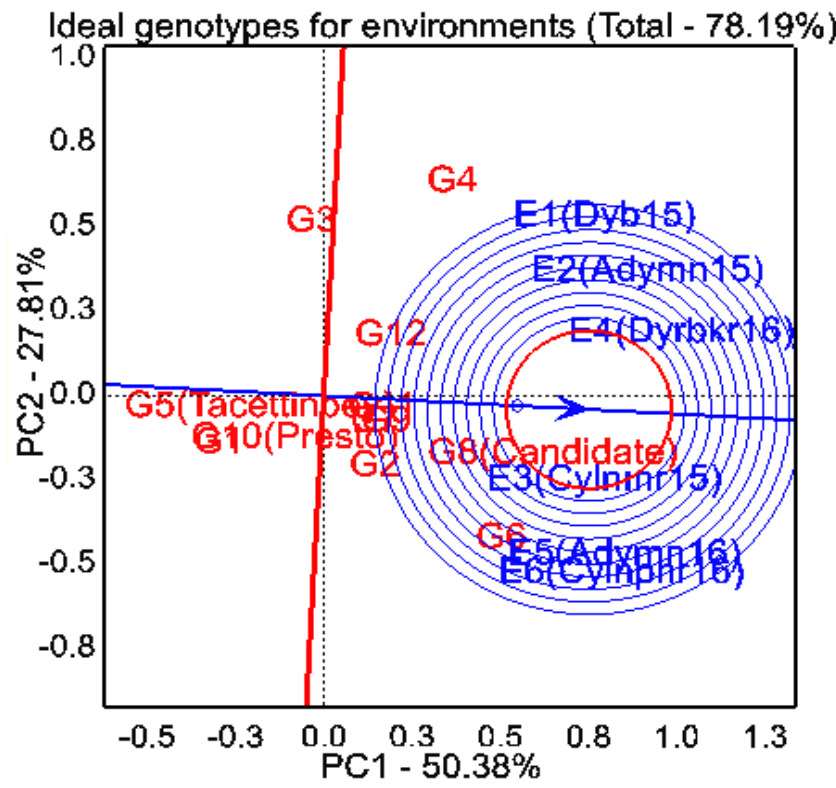

Figure 6. The comparison method rank the genotypes to an ideal genotype. The ideal genotype can be used as a reference for genotype evaluation. Thus, using the ideal genotype as the center, concentric circles were drawn to help visualize the distance between each genotype and the ideal genotype. G1-G12 is the codes for the triticale disomic addition lines and G5 and G10 used as the control, respectively. E1- E3 are environment codes for 2014-15, E4-E6 for 2015-16 growing season 


\section{Discussion}

The multiple environments experiments aims to identify superior genotypes for different conditions. Due to the unpredictable environmental factors, different models (GE, GEI, GGE, AMMI) were developed to elucidate the effect of genotype, environment or interaction, and are still used in breeding studies (Kendal and Sayar, 2016; Kendal et al., 2016). In addition, The AMMI and GGE biplot techniques have been used for a long time by many researchers to understand the effect of genotype, environment and GEI based on grain yield (Yan and Tinker, 2006; Kendal and Dogan, 2015; Akcura et al., 2016; Oral et al., 2018). The AMMI analysis was used to identify the stability and superiority of genotypes, favorable and yielding environments based on multiple environments (Tekdal and Kendal, 2018). In the study AMMI analysis indicated that G4 and G6 were yielding genotypes, while G7 and G8 (candidate) were stable in tested environments. On the other hand, the study showed that the grain yield is fluctuation depend on factors of environmental and years. In addition, some locations (Diyarbakır) have proven to be highly yielding, some other locations (Ceylanpinar) have proven to be low-yielding even if the year conditions change. Some studies on AMMI commented that this model can be used to describe a two-way table of GE means. When the GE means are independent and homoscedastic, ordinary least squares (OLS) gives optimal estimates of the model (Gauch et al., 2008), this model could be used to evaluate genotypes at different locations over the years in breeding program (Sadeghzadeh et al., 2017). The magnitude of environment effect was higher than genotype effect ( $\operatorname{Rad}$ et al., 2013). In triticale the locations that are both descriptive and representative are good test locations for the selection of adapted genotypes (Bilgin et al., 2018). Acording to GGE biplot biplot showed that the selection of genotypes can be done both on spesific and general goals. In the study, two mega-environment were occured in the test environments and G4 was the best yielding in the poorest environments or years, and G6 for yielding crop seasons or environments, while G8 (candidate) is stabile for general testing environments. According to results of a study indicated that an ideal genotype should have both high mean yield and high stability within a mega-environment (Yan and Tinker, 2006). In studies conducted in different years or environments, if there is no difference between two or more environments and within the same circle, this is called mega environment and it is recommended to work in one of these environmental groups in later studies. Fortunately, more than two megaenvironments are often sufficient to allow GE to capture a sizeable portion of the interaction signal (Gauch, 2013; Hongyu et al., 2015). According to the results of the AMMI and GGE biplot models had similar results in view of specific adaptability to environmental conditions. Nevertheless, contrary results were obtained for environmental contribution to the stability of genotypes (Lule et al., 2014; Shahriari et al., 2018). Both AMMI and GGE were able to efficiently explore the variability present in MET data due to genotype-environment interaction and both models proved to be approximately equivalent, leading to substantially the same conclusions about the genotypes with the highest yield and stability (Neisse et al., 2018).

\section{Conclusion}

The results of study revealed that grain yield of triticale was highly influenced by environment effect followed by genotypic effects and GEI contributed the least. This study demonstrated that AMMI model was found effective for determining the yielding 
and stabilite triticale genotypes and discriminating ability and representativeness of the test environments. Acording of the study, G4 and G6 showed specific ability, while G8 general adaptability in test environments. Moreover; G4 can be reccomend for yielding (mega-env II), while G6 for low-yielding (Mega-env. I) seasons or environments. On the other hand, G8 can be registared as variety for study area, because this genotype is quite stable and yielding among genotypes in test environments. Both AMMI and GGE biplot model were proved to be approximately equivalent, leading to substantially the same conclusions about the genotypes with the highest yield and stability.

\section{REFERENCES}

[1] Akcura, M., Kokten, K., Akcacik, A. G., Aydogan, S. (2016): Pattern analysis of Turkish bread wheat landraces and cultivars for grain and flour quality. - Turkish J. of Field Crops 21(1): 120-130.

[2] Anonymus 1. (2018): http://www.fao.org/home/en/.

[3] Anonymus 2. http://www.factfish.com/statistic/triticale\%2C\%20production\%20quantity.

[4] Ayalew, H., Kumssa, T. T., Butler, T. J., Ma, X. F. (2018): Tritical improvement for forage and cover crop uses in the Southern Great Plains of the United States. - Frontiers in plant science 9 .

[5] Bilgin, O., Balkan, A., Korkut, Z. K., Başer, I. (2018): Multi-environmental evaluation of Triticale, Wheat and Barley genotypes by GGE biplot analysis. - Journal of Life Sciences 12: 13-23.

[6] Crossa, J., Gauch, H. G., Zobel, R. W. (1990): Additive main effects and multiplicative interaction analysis of two international maize cultivar trials. - Crop Sci. 30: 493-500.

[7] Gauch, H. G., Piepho, H. P., Annicchiarico, P. (2008): Statistical analysis of yield trials by AMMI and GGE: further considerations. - Crop Science 48: 866-889.

[8] Gauch, H. G. (2013): A simple protocol for AMMI analysis of yield trials. - Crop Science 53(5): 1860-1869.

[9] Hongyu, K., Silva, F. L., Oliveira, A. C. S., Sarti, D. A., Araújo, L. C., Dias, C. T. S. (2015): Comparação entre os modelos AMMI e GGE Biplot para os dados de ensaios multi-ambientais. - Rev. Bras. Biom., São Paulo 33(2): 139-155.

[10] Kendal, E., Dogan, Y. (2015): Stability of a candidate and cultivars (Hordeum vulgare L) by GGE Biplot analysis of Multi-environment yield trials in spring barley. - Agriculture \& Forestry 61(4): 307-318.

[11] Kendal, E., Sayar, M. S. (2016): The stability of some spring triticale genotypes using biplot analysis. - The J. of Animal \& Plant Sci. 26(3): 754-765.

[12] Kendal, E., Sayar, M. S., Tekdal, S., Aktas, H., Karaman, M. (2016): Assessment of the impact of ecological factors on yield and quality parameters in triticale using GGE biplot and AMMI analysis. - Pak. J. Bot. 48(5): 1903-13.

[13] Kendal, E., Tekdal, S. (2018): AMMI model to assess durum wheat genotypes in multienvironment trials. - J. Agr. Sci. Tech. 20: 153-166.

[14] Kilic, H. (2014): Additive main effect and multiplicative interactions (AMMI) Analysis of grain yield in barley genotypes across environments. - J. Agr. Sc. 20: 337-344.

[15] Kizilgeçi, F. (2019): Assessment of yield and quality of some Triticale genotypes in South-Eastern Anatolia. Journal of the Institute of Sci. and Technology, 9(1): 545-551.

[16] Lule, D., Tesfaye, K., Mengistu, G. (2014): Genotype by environment interaction and grain yield stability analysis for advance triticale (X. Triticosecale Wittmack) genotypes in western Oromia, Ethiopia. - SINET: Ethiopian Journal of Science 37(1): 63-68.

[17] Mohammadi, R., Armion, M., Zadhasan, E., Ahmadi, M. M., Amri, A. (2018): The use of AMMI model for interpreting genotype $\times$ environment interaction in durum wheat. Experimental Agriculture 54(5): 670-683. 
[18] Neisse, A. C., Kirch, J. L., Hongyu, K. (2018): AMMI and GGE Biplot for genotype $\times$ environment interaction: a medoid-based hierarchical cluster analysis approach for highdimensional data. - Biometrical Letters 55(2): 97-121.

[19] Oral, E. (2018): Effect of nitrogen fertilization levels on grain yield and yield components in triticale based on AMMI and GGE biplot analysis. - Applied Ecology and Environmental research 16(4): 4865-4878.

[20] Oral, E., Kendal, E., Dogan, Y. (2018): Selection the best barley genotypes to multi and special environments by AMMI and GGE biplot models. - Fresenius Environmental Bulletin 27(7): 5179-5187.

[21] Purchase, J. L. (1997): Parametric analysis to describe $G \times E$ interaction and yield stability in winter wheat. - PhD. Thesis, Department of Agronomy, Faculty of Agriculture, University of the Orange Free State, Bloemfontein, Shout Africa.

[22] Rad, M. N., Kadir, M. A., Rafii, M. Y., Jaafar, H. Z., Naghavi, M. R., Ahmadi, F. (2013): Genotype environment interaction by AMMI and GGE biplot analysis in three consecutive generations of wheat (Triticum aestivum) under normal and drought stress conditions. - Australian J. of Crop Science 7(7): 956.

[23] Sadeghzadeh, B., Mohammadi, R., Ahmadi, H., Abedi, A. G., Khalilzadeh, G., Mohammadfam, M., Hasanpour, H. M. (2017): Efficiency of GGE biplot and AMMI analyses for adaptaility and grain yield stability of durum wheat lines under different environments. - Journal of Crop Ecophysiology (agriculture science) 11, 2(42): 413-436.

[24] Shahriari, Z., Heidari, B., Dadkhodaie, A. (2018): Dissection of genotype $\times$ environment interactions for mucilage and seed yield in Plantago species: Application of AMMI and GGE biplot analyses. - PloS one 13(5): e0196095.

[25] Tekdal, S., Kendal, E. (2018): AMMI model to assess durum wheat genotypes in multienvironment trials. - J. Agr. Sci. Tech. 20: 153-166.

[26] Yan, W., Hunt, L. A., Sheng, Q., Szlavnics, Z. (2000): Cultivar evaluation and megaenvironment investigation based on the GGE biplot. - Crop Science 40(3): 597-605.

[27] Yan, W., Rajcanw, I. (2002): Biplot analysis of test sites and trait relations of Soybean in Ontario. - Crop Sci. 42: 11-20.

[28] Yan, W., Tinker, N. A. (2006): Biplot analysis of multi-environment trial data: Principles and applications. - Canadian journal of plant science 86(3): 623-645.

[29] Zobel, R. W., Wright, M. S., Gauch, H. G. (1988): Statistical analysis of a yield trial. Agronomy Journal 80: 388-393.

\section{APPENDIX}

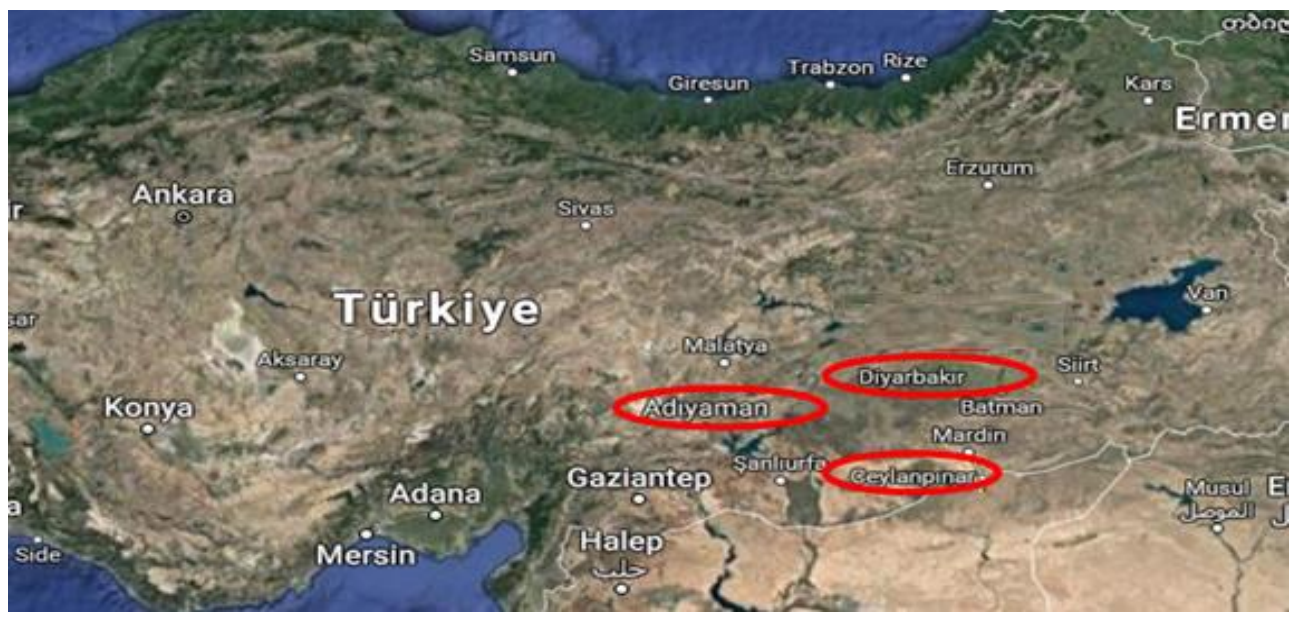

Picture 1. The locations of research was presented in Southeast Anatolia of Turkey 